\title{
UMA ABORDAGEM TEÓRICO-CONCEITUAL SOBRE POLÍTICAS PÚBLICAS, MODELOS DE ESTADO E ATUAÇÃO DO JUDICIÁRIO BRASILEIRO
}

Andrea Abrahão Costa

Doutoranda em Direito (PUC/PR). Mestre em Direito Econômico e Socioambiental (PUC/PR). Pós-graduada em Sociologia (UNICAMP). Professora do Curso de Direito da Fundação de Estudos Sociais do Paraná. Advogada.

Claudia Maria Barbosa Doutora em Direito pela Universidade Federal de Santa Catarina. Professora Titular de Direito Constitucional da Pontifícia Universidade Católica do Paraná. Professora permanente do Mestrado e Doutorado em Direito da PUCPR.

\section{Resumo}

Desde a consolidação de regimes democráticos ocidentais, o tema das políticas públicas ocupa maior destaque no cenário acadêmico e foi tomado como objeto de estudo por diferentes ramos do conhecimento. No presente trabalho procura-se mapear os diversos conceitos construídos para as políticas públicas, com o objetivo de tentar responder a três indagaçôes: o que seriam as políticas públicas, quais as teorias que poderiam ser usadas para lhes dar sustentaçáo e em qual contexto histórico a discussão teria surgido. Ademais, procura-se sistematizar a interação entre políticas públicas e direito a partir de três vertentes: da sua inserção no contexto do Estado Constitucional, da emergência do fenômeno da judicialização da política e da sua relaçáo com as noçóes que informam a governança pública. Afirma-se, por fim, que a problematizaçáo apresentada tem como objetivo contribuir para o início da construçáo de um campo de análise propriamente jurídico das políticas públicas.

\section{Palavras-chave}

Estado Constitucional; Políticas Públicas; Governança Pública; Poder Judiciário.

\section{Abstract}

Since the consolidation of Western democratic regimes, the issue of public policy takes greater prominence in the academic setting and was taken as an object of study 
by different branches of knowledge. In the present paper attempts to map the various concepts built for public policy, in order to try to answer three questions: what would be the public policy, which the theories that could be used to give them support and what historical context discussion would have appeared. In addition, it seeks to systematize the interaction between public policy and law from three aspects: their integration in the context of the Constitutional State, legalization of phenomenon of emergence of the policy and its relationship with the notions that inform the public governance. It is stated, finally, that the presented questioning aims to contribute to the start of construction of a proper legal analysis of the field of public policy.

\section{Key words}

Constitutional State; Public Policy; Public Governance; Judiciary.

\section{Introdução}

Nem tudo é o que parecer ser. É o que ocorre com as políticas públicas. Seriam elas monopólio do Estado? Políticas públicas comportariam o conceito de políticas de governo? Políticas públicas e políticas sociais teriam o mesmo sentido? Constituiriam as políticas públicas uma disciplina autônoma? Estas as perguntas nem sempre fáceis de serem respondidas, sendo lugar comum afirmar que tal se dá em decorrência da polissemia do termo. $\mathrm{O}$ esforço está posto para quem deseja fazer o uso científico da expressão. Sabe-se que ela integra trabalhos de ciência política, sociologia, administração, economia e direito e em cada um destes ramos do conhecimento seus contornos sofrem alteraçóes, dadas as explicaçóes sobre a sua natureza e seus processos.

No presente estudo, de cunho eminentemente teórico, mas sem pretensão de exaurir o tema, procura-se sistematizar, primeiramente, diferentes olhares conceituais, na tentativa de responder o que seriam as políticas públicas, quais as teorias que poderiam ser usadas para lhes dar sustentação e em qual contexto histórico a discussão teria surgido.

$\mathrm{Na}$ segunda parte, tendo como mote a interação entre direito e políticas públicas, sustenta-se ser impossível dissociá-las do modelo de Estado no qual se desenrolam e, com isso, procura-se problematizar o tema a partir de um duplo viés - (i) do chamado movimento de judicialização da política e (ii) da contribuição de estudos de governança pública.

Trata-se, portanto, de um estudo não exaustivo, que inclui literatura não restrita à área jurídica e, por isso mesmo, procura demonstrar como ela faz uso limitado dos diversos conceitos de políticas públicas, identificando-as, no mais das vezes, com as políticas sociais, fruto que são do processo de redemocratização do Brasil. 
Apesar de não privilegiar o efeito das políticas públicas, como tradicionalmente tem ocorrido nos estudos meramente descritivos levados a efeito no Brasil ${ }^{1}$, cuja ênfase é na análise das estruturas e instituiçóes ou na caracterização dos processos de negociação de políticas setoriais específicas, o que se pretende, de modo singelo, é iniciar uma contribuição para a construção de um campo de análise propriamente jurídico das políticas públicas $^{2}$.

\section{Os Diversos Conceitos de Políticas Públicas}

A autonomização dos estudos de políticas públicas deu-se, como explica Souza (2006, p. 22), como um terceiro momento nas análises empreendidas pela ciência política. Como subárea de investigação, está mais ligada ao como e por quais razóes governos optam por determinadas açóes. Tem como pressuposto analítico a constatação de que em democracias estáveis aquilo que o governo faz ou deixa de fazer pode ser formulado e analisado cientificamente.

No mesmo sentido explica Frey (2000, p. 213). Inicialmente o questionamento da ciência política centrava-se no sistema político como tal, ou seja, saber qual o melhor Estado para garantir e proteger a felicidade dos cidadãos ou da sociedade. Mas, a ciência política não descurou das forças políticas cruciais envolvidas no processo decisório e dos resultados que um dado sistema político, a partir de certas estratégias, logra alcançar para a solução de problemas específicos.

Di Giovanni (2009, p. 7), de outro giro, chama a atenção para a origem do tema, ainda nos anos anteriores a 1960 . Destaca que foram as pesquisas realizadas durante a $2^{\text {a }}$ guerra por países envolvidos no conflito e sobre o perfil dos soldados americanos, que forneceram subsídios para a ação dos governos e influenciaram a introdução da política pública como ferramenta das decisôes. Política pública aqui é vista como produto da Guerra Fria e da tecnocracia como forma de enfrentar suas consequências. Pela atuação do então Secretário de Defesa dos Estados Unidos, Robert MacNamara, a guerra passou a ser vista como um jogo racional e os métodos ali aplicados para a formulação de açóes e tomada de decisóes acabou por se expandir para outras áreas do governo.

1 A esse respeito conferir FREY, Klaus. Políticas públicas: um debate conceitual e reflexóes referentes à prática da análise de políticas públicas no Brasil. Planejamento e Políticas Públicas, Brasília, n. 21, 2000. Disponível em: <http://www.ipea.gov.br/ppp/index.php/PPP/article/view/89 > Acesso em: $23 \mathrm{dez}$ 2014.

2 Com preocupação semelhante, Bucci e Santos refletem sobre a existência de um regime jurídico das políticas públicas e defendem que seu estudo deveria ocorrer no âmbito do Direito Administrativo, já que este é o ramo que cuida da racionalização formal do poder pelas funçóes do governo. BUCCI. Maria Paula Dallari. Direito Administrativo e Políticas Públicas. São Paulo: Saraiva, 2002, p. 265. SANTOS, Maria Lourido dos. Interpretaçáo constitucional no controle judicial das políticas públicas. Porto Alegre: Sergio Antonio Fabris Editor, 2006, p. 76-77. 
Importante diferença realizada pela tradição norte-americana quanto ao termo política também deve ser colocada em destaque quando se está a construir um conceito de políticas públicas. Sabe-se que a política em inglês possui dois desdobramentos. Tanto quer significar fenômenos do poder - partidos, eleiçóes, representação política - e, nesse sentido, será chamada de politics, quanto formas de ação e conduta para a soluçáo de problemas no campo da administração, sendo denominada de policy. A vantagem, afirmaria Harold Lasswell (apud SOUZA, 2006, p. 23), identificado como um dos pais fundadores da área de políticas públicas ${ }^{3}$, é que o termo policy studies teria o condão de livrar os estudos de uma conotação de militância. Souza (2006, p. 23) ainda destaca a contribuição de dois outros autores, David Easton e Herbert Simon. Para aquele, políticas públicas são um sistema, configuram uma relação entre formulação, resultados e ambiente, e recebem inputs de partidos, mídia e grupos de interesses, que acabam por influenciar os resultados e seus efeitos. Já Simon, destaca Souza (2006, p. 24):

[...] introduziu o conceito de racionalidade limitada dos decisores públicos (policy makers), argumentando, todavia que a limitaçáo da racionalidade poderia ser minimizada pelo conhecimento racional. [...] a racionalidade dos decisores públicos é sempre limitada por problemas tais como informação incompleta ou imperfeita, tempo para a tomada de decisão, auto-interesse dos decisores, etc., mas a racionalidade, segundo Simon, pode ser maximizada até um ponto satisfatório pela criação de estruturas (conjunto de regras e incentivos) que enquadre o comportamento dos atores e modele esse comportamento na direção de resultados desejados $[\ldots]$

A despeito de importante contribuição, a limitação dos estudos norte-americanos vem sendo apontada pelo viés da impossibilidade de generalização de seus resultados, sobremodo porque não desvendaram as relaçôes complexas entre formas de intervenção do Estado, bem assim as relaçóes entre os diferentes interesses, estruturas políticas, ideologias e a própria natureza do Estado interventor. Daí poder-se afirmar que aquela constituiria uma abordagem restritiva, com viés pragmático, de análise apenas dos fins e impactos das políticas, sem que se atente para o potencial analítico das políticas públicas.

A esse respeito e não pertinência de sua aplicação no Brasil explica Frey (2000, p. 215):

Na verdade, a falta de teorização é uma crítica comumente direcionada à 'policy analysis'. Porém, a falta de teoria é explicável, se levarmos em consideração o interesse de conhecimento próprio da 'policy analysis', que é, a saber, a empiria e a prática política. Enquanto alguns dos críticos

3 SOUZA afirma que continua sendo de Laswell a definiçấo de políticas públicas mais conhecida: deve-se responder quem ganha o quê, por quê e que diferença faz. 
até chegam a contestar a cientificidade da 'policy analysis' pela falta de teorização, para Wollmann, ao contrário, a 'policy analysis' contém o potencial analítico de superar uma abordagem isolada que dá prioridade ou à dimensão institucional ('polity') ou à dimensão político-processual, ao deixar confluir a dimensão material de política (isto é, fins, impactos, etc.) com as dimensóes institucional e político-processual. [Wollmann, 1985, p. 74]. No que diz respeito à 'policy analysis' nos países em desenvolvimento, é preciso levar em consideração o fato de que o instrumento analítico-conceitual (deficitário) foi elaborado nos países industrializados e, portanto, é ajustado às particularidades das democracias mais consolidadas do Ocidente. Defendo a tese de que as peculiaridades socioeconômicas e políticas das sociedades em desenvolvimento não podem ser tratadas apenas como fatores específicos de 'polity' e 'politics', mas que é preciso uma adaptação do conjunto de instrumentos da análise de políticas públicas às condiçóes peculiares das sociedades em desenvolvimento.

Sobre a polissemia do termo políticas públicas, boa sistematização foi feita por Lima (2012, p. 51). Aponta o autor a possibilidade de ampliaçáo do conceito levando-se em consideração o protagonista do processo, mencionando, para tanto, duas teorias, a estatista e a multicêntrica. Para a primeira apenas o que emana do poder estatal pode ser chamado de política pública.

A [...] state-centered policy-making segundo Secchi [...] considera as políticas públicas, analiticamente, monopólio de atores estatais. Segundo esta concepção, o que determina se uma política é ou não 'pública' é a personalidade jurídica do formulador. Em outras palavras, é política pública somente quando emanada de ator estatal [...]. Nesta mesma linha de pensamento Salisbury (1995) argumenta que a política pública consiste em decisôes autorizadas ou sancionadas pelos atores governamentais. Política pública aqui significa os resultados ou saídas de processos governamentais. Para Rua (2009), que enfatiza mais a questão, a dimensão pública de uma política é dada pelo seu caráter jurídico imperativo, assim políticas públicas (policy) compreendem o conjunto das decisóes e açóes relativas à alocação imperativa de valores envolvendo bens públicos. Complementa dizendo que açôes e decisôes privadas, ainda que sejam de interesse público não se confundem com atividade política e com política pública.

A teoria multicêntrica, de outro lado, considera que o mais importante não é de quem emana a solução do problema, mas, sim, a origem do problema. Se este for público a política será pública e, com isso, caminha-se para além da ideia de políticas governamentais. Nesta perspectiva, o que interessa ao conceito é que outros organismos da comunidade política podem promover políticas públicas, como ocorre com organizaçóes privadas, organizaçóes não governamentais, organismos multilaterais e redes de políticas públicas (policy networks). 
Ainda, para se escapar do reducionismo ocasionado por um viés eminentemente prático, que privilegia os efeitos das políticas públicas, importante é a contribuição de Di Giovani (2009, p. 11) quando propóe um conceito evolutivo que abarque as constantes transformaçóes históricas nas relaçóes entre Estado e sociedade e, com isso, considere as mediaçóes que estão referidas aos processos de democratização das sociedades contemporâneas. Seu modelo de análise permite identificar quatro elementos invariantes das políticas públicas, de ordem formal, material, substancial e simbólica ${ }^{4}$.

Souza (2006, p. 25) vai em sentido semelhante quando defende um conceito holístico para as políticas públicas, significando que o todo é mais importante que a soma das partes e, assim, tanto indivíduos, quanto instituiçóes, interaçóes, ideologia e interesses, todos estes elementos contam para a construção do fenômeno, mesmo que sejam consideradas as diferenças sobre a importância relativa de cada qual. Trata-se, portanto, de mais um conceito ampliativo, que considera a política pública como sendo o campo do conhecimento que busca a um só tempo colocar o governo em ação e/ou analisar essa ação e, eventualmente, propor mudanças no rumo ou no curso dessas açóes.

Outras diferenciaçôes são comumente feitas no Brasil, ora identificando-se o fenômeno das políticas públicas com programas de ação governamental, ora com atividades administrativas, ora, ainda, com processos juridicamente regulados. Nesse sentido, para Comparato (1998, p. 34) "a política aparece, antes de tudo, como uma atividade, isto é, um conjunto organizado de normas e atos tendentes à realização de um objetivo determinado." Freire Júnior (2005, p. 47) afirma que "a expressão pretende significar um conjunto ou uma medida isolada praticada pelo Estado com o desiderato de dar efetividade aos direitos fundamentais ou ao Estado Democrático de Direito.” De outro lado, Couto (2006, p. 99) pondera que "é política pública tudo aquilo que o Estado gera como resultado de seu funcionamento ordinário”. Já Bucci (2002, p. 29) propóe que:

Política pública é o programa de ação governamental que resulta de um processo ou conjunto de processos juridicamente regulados - processo eleitoral, processo de planejamento, processo de governo, processo orçamentário, processo legislativo, processo administrativo, processo judicial - visando coordenar os meios à disposiçáo do Estado e as atividades privadas, para a realizaçáo de objetivos socialmente relevantes e politicamente determinados. Como tipo ideal, política pública deve visar a realização de objetivos definidos, expressando a seleção de prioridades, a reserva de meios necessários à sua consecução e o intervalo de tempo em que se espera o atingimento dos resultados.

Por fim, na tentativa de diferenciar política de Estado de política de governo, Aith (2006, p. 235) considera a proteção e promoção dos direitos humanos como ponto fulcral e sustenta:

4 Para o aprofundamento do apontado modelo de análise ver: DI GIOVANNI, Geraldo. Op. cit. 
Quando a política pública tiver como objetivos a consolidação institucional da organização política do Estado, a consolidação do Estado Democrático de Direito e a garantia da soberania nacional e da ordem pública, ela poderá ser considerada política de Estado. Dentro desse quadro, pode-se afirmar, ainda, que uma política é de Estado quando voltada a estruturar o Estado para que este tenha as condiçôes mínimas para a execução de políticas de proteção e promoção dos direitos humanos. Quando, de outro lado, os objetivos das políticas públicas forem o de promover açôes pontuais de proteção e promoção aos direitos humanos específicos expressos em nossa Carta, pode-se falar em política de governo.

Constatada a extensa gama de abordagens, passa-se, então, à sistematização da necessária relação entre as políticas públicas e o modelo de Estado no qual estão inseridas, com o objetivo de, ao final, reafirmar-se que, gradativamente, o campo do debate político deixou de ser o regente exclusivo das políticas públicas, assim como identificar-se qual tem sido a marca da atuação do Judiciário brasileiro a partir da consolidação do regime democrático.

É o que será abordado a seguir.

\section{Interação entre Direito e Políticas Públicas}

\subsection{Políticas Públicas e Modelos de Estado}

Não se nega que visôes diferentes de sociedade e de Estado geram projetos diferentes para as políticas públicas. E, nesse sentido, ao serem eleitas como objeto de estudo, as políticas públicas conduzem à necessária investigação sobre esta interrelação - Estado, política e sociedade. Sua índole política é inafastável. Mas, para os fins do que se pretende no presente estudo, dá-se destaque, especificamente, à sua necessária relação com o modelo de Estado no qual são concebidas e implementadas, tendo-se como foco o próprio caso brasileiro.

A afirmação não é nova: o marco de transformação de um modelo de Estado para outro no Brasil foi a promulgação da Constituiçáo da República de 1988. Esta, instaura a passagem de um Estado de Direito para o que se passou a denominar de Estado Constitucional, o qual, dentre outras características erige as políticas públicas como um meio imprescindível para a sua atuação. Mas isto não se dá por acaso. Diversamente do anterior Estado de Direito, submetido à lei e possuidor de um ideário iluminista e liberal, no Estado Constitucional o Estado passa a vincular-se ao alcance de objetivos axiológicos, como a superaçáo de desigualdades materiais, garantia da democracia e realização da justiça substancial.

A conformação deste novo tipo de Estado vem bem sintetizada no pensamento de Zagrebelsky (2011, p. 34): 
La respuesta a los grandes y graves problemas de los que tal cambio es consecuencia, y al mismo tempo causa, está contenida em la fórmula del 'Estado constitucional'. La novedad que la misma contiene es capital y afecta a la posición de la ley. La ley, por primeira vez em la época moderna, viene sometida a uma relación de adecuación, y por tanto de subordinación, a um estrato más alto de derecho estabelecido por la Constitución. ... Con ello, podría decirse, se realiza de la forma más completa posible el principio del gobierno de las leyes, em lugar del gobierno de los hombres, principio frecuentemente considerado como uma de las bases ideológicas que fundamentam el Estado de derecho. Sin embargo, si de las afirmaciones genéricas se passa a comparar los caracteres concretos del Estado de derecho decimonónico con los del Estado constitucional actual, se advierte que, más que de uma continuación, se trata de uma profunda transformación que incluso afecta necessariamente a la concepción del derecho.

A relação entre políticas públicas e um tipo específico de Estado é explicitada por Breus (2006, p. 176) de maneira mais intensa, quando o autor defende que a forma de atuação específica do Estado Constitucional é exatamente a política pública, propondo com isso uma necessária circunscrição jurídica do tema na contemporaneidade, apesar de assumir que ele possui uma raiz ontologicamente política e não jurídica. E isso porque, sustenta o autor, "o exame das políticas públicas requer análise sobre o atual estágio de desenvolvimento das formas de atuação do Estado para a realização dos Direitos Fundamentais sociais, econômicos e culturais." Ou, dito de outra forma, porque o objeto destes direitos é sempre uma política pública. E sobre esta relação acrescenta Breus (2006, p. 170):

Ampliando-se, pois, as politicas públicas como o mecanismo por excelência de ação estatal, estar-se-á divulgando um discurso jurídico de efetivação das normas constitucionais, em especial dos Direitos Fundamentais sociais, haja vista que eles terão um meio adequado e abrangente para serem realizados. Isso porque, [...] 'adotar a concepção das políticas públicas em direito consiste em aceitar um grau maior de interpenetração entre as esferas jurídica e política ou, em outras palavras, assumir a comunicação que há entre os dois subsistemas, reconhecendo e tornando públicos os processos dessa comunicação na estrutura burocrática do poder, Estado e Administração Pública.

Sob outro enfoque, explicam Trevisan e Van Bellen (2008, p. 532), que o maior interesse pela temática das políticas públicas ocorreu na década de 1980 em função dos influxos democráticos e da alteração do conteúdo da agenda pública. De questóes eminentemente centradas no modelo de desenvolvimento do Estado na década anterior, passou-se à investigação não mais de aspectos redistributivos da ação governamental, mas de temas ligados à descentralizaçáo, participação e transparência arregimentados em torno 
da preocupação crescente com a efetividade da ação pública. Eram tempos da propalada ideia internacional de reforma do Estado, que se estendeu até o fim dos anos 1990, e do aprofundamento da crise do Welfare State, surgindo o movimento da chamada nova administração pública.

Esta outra forma de se enxergar a relação entre políticas públicas e modelos de Estado, mais relacionada com estudos de gestão administrativa, parte da ideia de que as teorias tradicionais da burocracia passaram a ser questionadas, já no início daquela década de 1980, quando tornou-se lugar comum falar de uma "crise de governabilidade" diante da prestação ineficiente de serviços públicos e, paulatinamente, de uma "crise de governança" mais ligada à ideia de déficit de legitimidade dos governos perante os cidadáos.

De um modelo inspirado pela racionalidade burocrática weberiana, marcado por procedimentos regulados e previsíveis e exercício impessoal de funçóes contínuas e específicas de um cargo, preconizou-se um modelo intitulado de New Public Management, que pudesse responder aos critérios de eficiência das açóes do Estado. E, a despeito das diferenças apontadas quanto a uma "Escola de Negócios" e outra "Escola de Políticas Públicas - a primeira com preocupação quanto a eficiência entre insumos e rendimentos (inputs-outputs) e a segunda mais atrelada à relação entre insumos e resultados (inputs-outcomes), ou seja, ao impacto de políticas sobre os cidadãos - diz-se que o modelo ideal gerencial é pautado pelas seguintes características: orientaçáo para clientes e resultados; flexibilidade; competitividade administrada; descentralização; atuação do Estado e não sua ausência completa; adoção de técnicas de administração privada com vistas à eficientização do sistema; estruturas horizontalizadas; instituição das agências reguladoras independentes; e relações administrativas firmadas por contrato de gestão.

No Brasil, como aponta Baldo (2009, p. 137):

[...] Luiz Carlos Bresser Pereira foi um dos poucos autores que conseguiu dar alguma notoriedade para o tema da gestão pública, chamando a atençấo dos cidadãos e não apenas dos "homens letrados" para a problemática [...]. Todavia, o apoio concedido pelo autor às reformas e a valorização de mecanismos privados de administração custaram-lhe diversas críticas e, possivelmente, o jargão de neoliberal. [...] Reconhecer que a aplicação da teoria da gestão pública pode fracassar na América Latina ou negar sua função legitimatória, a favor do viés "mercadológico" da gestão, não significa fechar-se à realidade [...], apegando-se a representaçôes passadas que já definharam. Além do mais, seria incongruente defender a "dignidade da pessoa humana" se houver o apego a modelos que esquecem o próprio homem, como pode ocorrer na lógica mecanicista do burocratismo autopoiético [...]

A propósito, o Plano Diretor da Reforma do Aparelho do Estado de 1995 (BRESSER PEREIRA, 1996) fixou quatro setores básicos que seriam objeto da passagem de 
um modelo burocrático de administração para um sistema gerencial. São eles: (i) núcleo estratégico composto pelos Poderes Legislativo e Judiciário, Ministério Público e parte do Poder Executivo encarregado da elaboração de políticas públicas; (ii) atividades exclusivas de Estado, indelegáveis, como ocorre com a fiscalização e cobrança de impostos, projetando-se a criação de agências autônomas; (iv) serviços não exclusivos, como os prestados por universidades e hospitais, prevendo-se a sua transferência para organizaçóes sociais; (v) produção de bens e serviços para o mercado, com planos de privatização dessas atividades.

A preocupação quanto à ameaça de autonomização radical da burocratização - burocracia como um "fim-em-si-mesmo" em flagrante isolamento da sociedade que a circunda - deve-se mencionar, não passou desapercebida por Max Weber, que a antevia como um possível risco às organizaçóes sociais e à própria conduta ética humana ${ }^{5}$, nem tampouco por Offe (1994, p. 222), que chamou a atenção para o grande dilema da ação administrativa contemporânea - a necessidade de ser adequada às normas e, ao mesmo tempo, teleológica. Se, tradicionalmente, uma administração legal-burocrática deve seguir um esquema normativo predeterminado e o princípio da legalidade da atuação estatal garante o seu controle e a previsibilidade das açóes, a eficiência das açóes do Estado, contudo, náo é avaliada pela estrita observância das normas, mas, sim, pela tentativa de alcance de suas funçôes, efeitos e resultados concretos.

Ocorre que, a implantação do apontado novo modelo administrativo no Brasil também não passou desapercebida pelos críticos do Estado Neo-liberal que, de modo concomitante, vinha se instalando no decorrer da década de 1990. Tanto é assim que, para o que interessa à reflexão sobre políticas públicas e modelo de Estado, mostra-se importante o pensamento de Nef (2010, p. 519-527) quando aponta que:

A fórmula da Nova Gestão Pública [...], com seus corolários de privatização, redução de pessoal, desregulamentação, localização e terceirização, tem efeitos potencialmente desestabilizadores na ausência de uma comunidade e de uma ordem política fortes e legítimas. Além do mais, sem uma sociedade civil coerente e vigorosa preexistente, a modernização administrativa é simplesmente um meio para um fim vazio. Redimensionar o governo, torna-lo mais transparente e publicamente responsabilizável, transformá-lo num mecanismo mais eficiente de serviços por si mesmo ou em parceria com organizaçóes privadas/ou voluntárias não são simplesmente medidas isoladas para assegurar 'melhor administração'. São todas manifestaçôes de um fundamento ideológico neoliberal mais amplo [...]. O papel do Estado nesse modelo é principalmente suplementar, isto é, sua diretriz principal é proteger o funcionamento do mercado e a propriedade privada.

Sob outro aspecto, asseveram criticamente Gabardo e Reis (2011, p. 121) que:

5 A esse respeito ver: BALDO, Rafael Antonio. Novos Horizontes para a Gestáo Pública. Op. cit., p. 41. 
A deturpação decorrente da formação de um "estamento burocrático", completamente afastado do modelo burocrático, propiciou o nascimento de um preconceito em relação ao próprio modelo; o preconceito tornouse resistência; a resistência tornou-se crítica; a crítica, mera negação. Sendo assim, ao invés de medidas tendentes a realinhar o regime a fim de aproximá-lo do ideal, tornou-se corrente a busca por desburocratização. Por este motivo é que o termo, de expressão da racionalidade impessoal característica do Estado Moderno, acabou por conotar um sistema lento, precário, inflexível e dispendioso; em suma: ineficiente.

Enfim, pode-se afirmar que os anos que se seguiram a 1990 náo corresponderam ao esperado em termos de maior eficiência e leveza da máquina administrativa, e, consequentemente, de boa resposta estatal na concretização de políticas públicas ${ }^{6}$. Tanto é assim que, mais recentemente, eclodiu uma nova mudança de paradigma com a emergência da chamada governança pública - Public Governance. A sua relação com a temática das políticas públicas é objeto do próximo tópico.

\subsection{Governança Pública e a Capacidade de Ação do Estado no Implemento de Políticas Públicas}

Sabe-se que o surgimento da expressão governance deu-se a partir de reflexóes havidas no seio do Banco Mundial que redundaram num documento datado de 1992, intitulado Governance and Development, com o objetivo de se conhecer as condições que garantiriam um Estado eficiente, com foco não somente nas implicaçóes econômicas da ação estatal, mas em suas dimensóes sociais e políticas. Nesse sentido, o termo está direcionado não apenas para o formato institucional do processo decisório, mas também para a articulação público-privado na formulação de políticas e maior abertura para a participação de setores interessados e de diferentes esferas de poder.

Ademais, tal noção também possui grande relação com o denominado Consenso de Washington ${ }^{7}$ e com o Acordo de Cotonou (Benin) ${ }^{8}$, podendo-se afirmar que, a partir

6 Até porque, como explica Nef, se ao tempo das reformas administrativas realizadas conviviam tendências patrimoniais e burocráticas, "a máquina administrativa do Estado não pode ser vista simplesmente como um instrumento de implementação de políticas. Também é um ator sociopolítico central [...], com uma multiplicidade de funçôes latentes relacionadas À manutenção da ordem sociopolítica.” NEF, Jorge. Op. cit., p.. 522.

7 Trata-se de um conjunto de propostas elaboradas em 1989 por diversas instituiçóes financeiras, como por exemplo, Banco Mundial e Fundo Monetário Internacional - FMI, resumidas em dez regras, tomando-se como base o pensamento do economista John Williamson. Em 1990, foi adotado como modelo pelo FMI para os países em desenvolvimento e em crise financeira. VILLANUEVA, Luis Aguillar. Gobernanza y gestión pública. México: Fondo de Cultura Económica, 2006. p. 48.

8 Com o objetivo de auxiliar a paz e a segurança, fomentar o desenvolvimento econômico, cultural e social de países africanos, do Caribe e Pacífico, assim como de contribuir para a estabilidade, o Acordo 
destes dois documentos, é que se consolida mundialmente a conceituação de "boa governança” como parte da agenda dos Estados na busca pela eliminação de desigualdades sociais e maior eficiência econômica.

Mas como conceituar cientificamente o termo? E como contextualizá-lo no debate sobre as políticas públicas para a identificação de algum ponto de contato entre um e outro?

A primeira tarefa ainda é desafiadora, tal como observam Kissler e Heidemann (2006). A complexidade e a abrangência do termo governança impedem que ele se expresse em apenas uma definição, sendo necessária a busca pelo contexto em que é aplicado, identificando-se o tipo de organização de que se fala. Genericamente, pode-se afirmar que governança é um termo utilizado tanto nas organizaçóes quanto na sociedade, nas quais identifica-se a articulação de pessoas e grupos com diferentes interesses e expectativas. Inclui, assim, relaçôes na esfera pública, os setores governamental, empresarial e terceiro setor. É assunto que interessa a diferentes campos científicos, como as relaçóes internacionais, teorias do desenvolvimento, administração privada e pública, ciência política e o direito, convergindo, entretanto, para a ideia de que serve como uma medida base da estabilidade e desempenho de uma sociedade.

Contudo, o ponto de partida para aclarar a expressão, sintetizado pelo programa das Naçôes Unidas para o desenvolvimento - PNUD, é o de que o desenvolvimento das instituições e processos devem ser mais sensíveis às necessidades dos cidadãos comuns. Por isso, a governança é um conjunto de regras, processos e práticas que orientam as relaçóes formais de poder de uma organização com seus públicos ou entre governos e governados. Dito de outra forma, governança significa (i) a capacidade de ação estatal na implementação de políticas e na consecução de metas coletivas, (ii) a expansão e o aperfeiçoamento dos meios de interlocuçáo e de administração dos conflitos de interesses, (iii) a capacidade de inserção do Estado na sociedade, rompendo com a tradição e governo fechado e enclausurado na alta burocracia governamental.

Já no campo jurídico, deve-se mencionar, há extensa teoria sobre afirmar-se ser a boa governança um direito fundamental, ligado à qualidade dos serviços prestados, inserindo-a no próprio desenvolvimento da formaçáo do Estado e alteraçóes sofridas. Nesse sentido, como explica Caldeira (2013, p. 26), apoiada na reflexão de Juarez Freitas:

de Cotonou (Benin) foi assinado no dia 23 de junho de 2000, por vinte anos, firmando parceria da Comunidade Europeia (e seus Estados-membros) e os Estados da África, Caribe e do Pacífico. Dentre outros aspectos, o Acordo visa à erradicação progressiva da pobreza e a inserção dos países desfavorecidos já abordados no espaço da economia global. UNIĀO EUROPÉIA. Acordo de Contonou. Disponível em <http://eur-lex.europa.eu/legal-content/PT/TXT/?uri=CELEX:22000A1215\%2801\%29>. Acesso em: 23 ago. 2014. 
Ao afirmarmos que a Boa Governança configura-se em direito fundamental, em verdade, estamos nos alinhando à linha de pensamento que sustenta a existência de direitos de quarta dimensão. Não há unanimidade na doutrina em relação à classificação dos direitos fundamentais de quarta dimensão (ou geraçấo) e, dentre aqueles autores que aceitam a sua existência, também inexiste consenso quanto ao seu conteúdo. Entretanto, sustentamos que a extensão desse direito de quarta dimensão está atrelada não só ao direito de participação direta no processo democrático, mas também, com maior amplitude, o de pleitear a busca de maneira mais responsável, ética e comprometida com a gestão pública. Em suma, o que é relevante nessa quadra da história (e isso é ressaltado pelos doutrinadores que se dedicam ao assunto), é que a pedra de toque da gestáo da coisa pública deve ser a qualidade dos serviços prestados, isto é, a Administração Pública deve centrar todos os seus esforços não mais na extensão dos serviços prestados (preocupaçáo observada nos anos 80 e 90), e sim na eficiência dos mesmos. Ou seja, que atenda satisfatoriamente às legítimas expectativas e necessidades dos cidadãos no atendimento de seus direitos.

Para a segunda tarefa, de identificação de um liame entre o conceito de políticas públicas e a noção de governança, constata-se, com base no apanhado feito por Souza (2006, p. 36), que, dentre os modelos de formulação de políticas públicas, há aquele que se vale da ideia de implementação de políticas públicas de caráter participativo, oportunizando a inserção de grupos sociais na formulação e acompanhamento daquelas. Daí afirmar a autora que "a política pública envolve vários atores e níveis de decisão, embora materializada através dos governos, e não necessariamente se restringe a participantes formais, já que os informais são também importantes."

Neste ponto, portanto, sustenta-se no presente estudo que o novo paradigma da governança pública, ao preconizar pelo prestígio de uma dimensão social da democracia para além de suas regras formais, propicia também um novo olhar no desenvolvimento de modelos de formulação e implementação de políticas públicas, fazendo com que elas venham, agora, marcadas pelo referido caráter participativo. E, se contemporaneamente a questão democrática vai mesmo além da consolidação das regras formais da democracia, sua sustentabilidade não pode descurar da produção de resultados socialmente desejados, sendo isto também o que se espera da formulação e implementação de políticas públicas.

Mas como, sob estes diferentes e novos influxos, agiu o Judiciário brasileiro? Algumas palavras sobre o movimento denominado de judicialização da política.

\subsection{O Movimento da Judicialização da Política}

A breve espaço, pode-se afirmar que o debate acerca das funçóes que o Poder Judiciário brasileiro assumiu desde a promulgação da Constituição da República de 1988 
vem sendo feito a partir de diferentes clivagens, que, no entanto, podem ser aglutinadas numa linha específica de investigação que se denomina de política judiciária. Seu conceito compreende o caráter estratégico da forma de organização judiciária na constituição do poder político e na mediação das relaçóes sociais, não se limitando ao estudo da estrutura jurídico-formal, senão porque busca mediações entre o Poder Judiciário, o sistema político e a sociedade.

Nesse contexto, um dos enfoques correntes é o da maior atividade judiciária desde a constitucionalização dos direitos e do reconhecimento da força normativa da Constituição, fatores que acabaram por dirigir a atuação do Poder Judiciário para questôes eminentemente políticas, num movimento identificado como sendo de judicialização da política, trazendo, com isso, certa preocupação no que respeita à legitimidade das decisóes e a identificação de uma crise em suas funções clássicas.

Nesse sentido observa Barroso (2005, p. 53-54) que:

Sob a Constituição de 1988, aumentou de maneira significativa a demanda por justiça na sociedade brasileira. Em primeiro lugar, pela redescoberta da cidadania e pela conscientização das pessoas em relação aos próprios direitos. Em seguida, pela circunstância de haver o texto constitucional criado novos direitos, introduzido novas açóes e ampliado a legitimação ativa para tutela de interesses, mediante representação ou substituição processual. Nesse ambiente, juízes e tribunais passaram a desempenhar um papel simbólico importante no imaginário coletivo. [...] Recuperadas as liberdades democráticas e as garantias da magistratura, juízes e tribunais deixaram de ser um departamento técnico especializado e passaram a desempenhar um papel político, dividindo espaço com o Legislativo e o Executivo. Tal circunstância acarretou uma modificação substantiva na relação da sociedade com as instituiçóes judiciais, impondo reformas estruturais e suscitando questôes complexas acerca da extensão de seus poderes.

Não contrasta com esta constatação as consideraçóes de Cittadino (2004, p. 105) para quem "[...] se observa uma ampliação do controle normativo do Poder Judiciário, favorecida pela Constituição de 1988, que, ao incorporar direitos e princípios fundamentais, configurar um Estado Democrático de Direito e estabelecer princípios e fundamentos do Estado, viabiliza uma ação judicial que recorre a procedimentos interpretativos de legitimação de aspiraçóes sociais.”

Especificamente no campo da ciência política o tema da judicialização assume, por vezes, uma faceta peculiar, de aproximação com a problemática do ativismo judicial, enfrentando, todavia, como aponta Koerner (2013, p. 74), a crítica de que ela seria simplificadora da prática judicial, a qual "constitui uma modalidade de ação institucionalizada que, numa dada configuração da formação social, efetua, programa e reflete os materiais 
do agregado jurídico do ponto de vista da problemática da justiça.” E, nesse sentido, muito embora o autor reconheça que para os estudos de políticas públicas "o ativismo, definido como orientação do juiz para contrariar a política majoritária" foi visto como "uma das condiçôes para a emergência da judicialização da política, que designa processos de mudança no papel e poderes dos juízes nas sociedades contemporâneas", afirma que desde a edição da Carta de 1988 a atuação do Judiciário não teria correspondido às potencialidades evidenciadas no texto constitucional, tendo os juízes permanecido de modo seletivo quanto ao uso de seus poderes. E, conclui:

No quadro político do início dos anos 1990, o STF conformou a jurisdição constitucional de modo a limitar a frequência e o alcance de sua atuação conforme prevista pela Constituinte. Ministros do antigo regime e os de orientação liberal elaboraram um regime jurisprudencial que concorreu para a estabilização democrática e a constituição de um regime liberalizante. Ou seja, o STF combinou efetivação e neutralização de regras constitucionais segundo os domínios e o seu sentido estratégico para a direção política do governo federal, voltado às reformas liberalizantes do Estado. ... O que tem sido chamado ativismo no Brasil resulta de uma aliança entre a presidência da República e elites jurídicas a partir de 2002, voltada a promover as políticas do novo governo e a configurar um novo regime governamental.

Mas, considerando que o interesse do presente estudo não é aprofundar as eventuais críticas àquela atuação do Judiciário, dada a sua limitação e o seu enfoque, apresenta-se como suficiente a constatação de que, como observa Coutinho (2010, p. 16), a intervenção ou correção realizada pelo Judiciário podem variar. Alguns juízes decidem pondo em andamento políticas para as quais o governo é omisso ou corrigindo seus rumos, enquanto outros se cingem a um controle formal, seja em relação ao cumprimento de prazos, seja na garantia de motivação de atos administrativos, sem que haja, contudo, a revisão do mérito de determinada política.

Por fim, considerando a importância que foi dada no presente estudo sobre os diversos conceitos de políticas públicas, talvez o mais significativo seja constatar que “[...] agindo ativamente o Judiciário, muitas vezes, náo demonstra capacidade de promover mudanças sociais abrangentes e de corrigir adequadamente o rumo das políticas públicas desde uma ótica substantiva ou distributiva", como bem pontua Coutinho (2010, p. 16).

\section{Conclusões}

No presente estudo partiu-se de uma revisão teórico-conceitual sobre as políticas públicas, demonstrando que se trata de um termo polissêmico. $\mathrm{O}$ mapeamento náo exaustivo realizado na primeira parte, destacou-se, serviu de base para chamar a atenção para 
a necessária ligação entre a conformação das políticas públicas e um dado modelo de Estado. Elegeu-se como protagonista o chamado Estado Constitucional em comparaçáo com o Estado de Direito.

Na segunda parte do estudo, recuperou-se a discussão levada a efeito a partir da crise enfrentada pelo Welfare State, para destacar as reformas do aparelho do Estado realizadas no Brasil, que redundaram na chamada nova administraçáo pública, bem assim na adoçáo do paradigma da chamada governança pública. Em relação a esta, procurou-se identificar um ponto de contato com o tema das políticas públicas, o que foi possível a partir da análise de um modelo de formulação de políticas que privilegia o caráter participativo.

Por fim, a partir do tema da judicialização da política, mas sem aprofundar todas as críticas existentes, chamou-se a atenção para o fato de que a atuação do Judiciário no implemento de direitos sociais e normas programáticas nem sempre é garantia de mudanças sociais abrangentes e de correção adequada do rumo das políticas públicas desde uma ótica substantiva ou distributiva.

\section{Referências}

AITH, Fernando. Políticas públicas de Estado e de governo: instrumentos de consolidação do Estado Democrático de Direito e de promoção e proteção aos direitos humanos. In: BUCCI, Maria Paula Dallari (Org.). Políticas Públicas: reflexóes sobre o conceito jurídico. São Paulo: Saraiva, 2006.

BALDO, Rafael Antonio. Novos Horizontes para a Gestáo Pública. Curitiba: Juruá Editora, 2009.

BANCO MUNDIAL. Relatório Técnico n. 319 do Banco Mundial. O Setor Judiciário na América Latina e Caribe. Elementos para Reforma. Redação: Maria Dakolias. Tradução: Sandro Eduardo Sardá. Washington, 1996.

BRESSER PEREIRA, Luiz Carlos. Da Administração Pública burocrática à gerencial. Revista do Serviço público, n. 47(1), jan./abril 1996. Disponível em: http://www. bresserpereira.org.br/papers/1996/95.AdmPublicaBurocraticaAGerencial.pdf> Acesso em: 20 jan. 2008.

BUCCI. Maria Paula Dallari. Direito Administrativo e Políticas Públicas. São Paulo: Saraiva, 2002.

BARBOSA, Claudia. A legitimidade do exercício da jurisdição constitucional no contexto da judicialização da política. In: BARRETO, V.; DUARTE, F. e SCHWARTZ, G. Curitiba, Direito da sociedade policontextural. Curitiba, Appris, 2013, p. 171193. 
BARROSO, Luís Roberto. Neoconstitucionalismo e constitucionalização do direito O triunfo tardio do Direito Constitucional no Brasil. In: Themis - Revista da Escola Superior da Magistratura do Estado do Ceará, 2005, p. 13-100. Disponível em http://www.egov.ufsc.br/portal/sites/default/files/anexos/32007-37579-1-PB.pdf. Acesso em: 02 abr.2014.

CALDEIRA, Ana Paula Canoza. O Direito a saúde e sua “curiosa” efetividade em Terrae Brasilis: do desafio da realização da boa governança a excessiva judicializaçáo. 2013. 227 f. Universidade do Vale do Rio dos Sinos - UNISINOS. Programa de pós-graduação em Direito, São Leopoldo, 2013. Nível doutorado. Disponível em: <http://biblioteca.asav.org.br/vinculos/000007/00000756.pdf>. Acesso em: 02 nov. 2014.

CITTADINO, Gisele. Poder Judiciário, ativismo e democracia. Alceu, v. 5, n. 9, p. 105113. Jul./Dez. 2004.

COMPARATO, Fabio Konder. Ensaio sobre o juízo de constitucionalidade de políticas públicas. In: Revista de Informação legislativa. Brasília a. 35 n. 138 abr./jun. 1998. Disponível em: <http://www2.senado.leg.br/bdsf/item/id/364> Acesso em: $22 \mathrm{dez}$ 2014.

COUTINHO, Diogo R. O direito nas políticas públicas. Disponível em: <www.cebrap.org.br>. Acesso em: $20 \mathrm{dez} 2014$.

COUTO, Cláudio Gonçalves. Política constitucional, política competitiva e políticas públicas. In: BUCCI, Maria Paula Dallari (Org.) Políticas Públicas: reflexóes sobre o conceito jurídico. São Paulo: Saraiva, 2006.

DI GIOVANNI, Geraldo. Estruturas elementares das políticas públicas. Cadernos de Pesquisa, NEPP/UNICAMP, no 82, 2009.

FREIRE JÚNIOR, Américo Bedê. O controle judicial de políticas públicas. São Paulo: Revista dos Tribunais, 2005.

FREY, Klaus. Políticas públicas: um debate conceitual e reflexóes referentes à prática da análise de políticas públicas no Brasil. Planejamento e Políticas Públicas, Brasília, n. 21, 2000. Disponível em: <http://www.ipea.gov.br/ppp/index.php/PPP/article/ view/89 > Acesso em: $23 \mathrm{dez} 2014$.

GABARDO, Emerson; REIS, Luciano Elias. O gerencialismo entre eficiência e corrupção: breves reflexôes sobre os percalços do desenvolvimento. In: SILVEIRA, Raquel D. da; CASTRO, Rodrigo A. P. de. (Org.). Estudos Dirigidos de Gestáo Pública na América Latina. Belo Horizonte: Fórum, 2011.

GONÇALVES, Alcindo. O conceito de governança. In: Anais do Conpedi. XIV Congresso. 2005. Disponível em http://conpedi.org.br/manaus/arquivos/anais/XIVCongresso/078.pdf. Acesso em: 13 jun. 2014. 
KISSLER, Leo; HEIDEMANN, Francisco G. Governança pública: novo modelo regulatório para as relaçôes entre estado, mercado e sociedade? In: Revista de Administração Pública. v. 40, n. 3. Rio de Janeiro. Mai/jun. 2006. Disponível em http://www. scielo.br/scielo.php?script=sci_arttext\&pid=S0034-76122006000300008. Acesso em: 12 jun. 2013.

KOERNER, Andrei. Ativismo judicial: jurisprudência constitucional e política no STF pós-88. In: Novos estudos, v. 96, jul. 2013, p. 69-85.

LIMA, Waner Gonçalves. Política Pública: discussão de conceitos. Interface (Porto Nacional), n. 05, 2012, p. 51. Disponível em: < http://www.ceap.br/material/ MAT26022013171120.pdf > Acesso em: 20 dez 2014.

MAGALHÂES, Juliana Neueschwander. Interpretando o direito como um paradoxo: observaçôes sobre o giro hermenêutico da ciência jurídica. In: BOUCAULT, CARLOS E. E Rodriguez, José R. Hermenêutica plural. São Paulo, Martins Fontes, 2002, p. 128-157.

NEF, Jorge. Administração Pública e reforma do setor público na América Latina. Im: Peters, B. Guy; PIERRE, Jon (Orgs.). Administraçáo Pública: Coletânea. Tradução de Sonia M. Yanamoto e Miriam Oliveira. ENAP. Brasília, 2010, p. 519-527.

OFFE, Claus. Critérios de racionalidade e problemas funcionais da ação político administrativa. In: Problemas estruturais do estado capitalista. Rio de Janeiro: Tempo Brasileiro, 1984.

SANTOS, Maria Lourido dos. Interpretaçáo constitucional no controle judicial das políticas públicas. Porto Alegre: Sergio Antonio Fabris Editor, 2006.

SOUZA, Celina. Políticas Públicas: uma revisão da literatura. Sociologias. Porto Alegre, ano 8, no 16, p. 20-45, jul./dez. 2006, p. 22.

TREVISAN, Andrei; VAN BELLEN, Hans Michael. Avaliação de Políticas Públicas: uma revisão teórica de um campo em construção. Revista de Administração Pública. Rio de Janeiro, n. 42(3), maio/jun 2008.

ZAGREBELSKY, Gustavo. El derecho dúctil. Ley, derechos, justicia. Madrid: Editorial Trotta, 2011. 